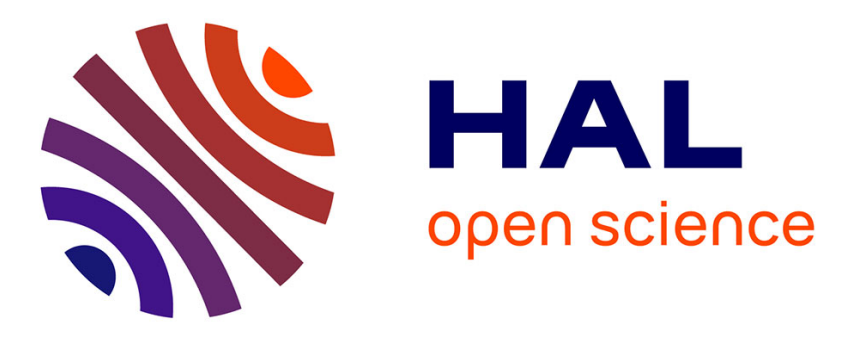

\title{
Characteristics of undiagnosed diabetes in community-dwelling French elderly: the 3C study.
}

Isabelle Bourdel-Marchasson, Catherine Helmer, Pascale Barberger-Gateau, Evelyne Peuchant, Benoit Février, Karen A. Ritchie, Jean-François Dartigues

\section{To cite this version:}

Isabelle Bourdel-Marchasson, Catherine Helmer, Pascale Barberger-Gateau, Evelyne Peuchant, Benoit Février, et al.. Characteristics of undiagnosed diabetes in community-dwelling French elderly: the 3C study.. Diabetes Research and Clinical Practice, 2007, 76 (2), pp.257-64. 10.1016/j.diabres.2006.09.003 . inserm-00173074

\section{HAL Id: inserm-00173074 https://www.hal.inserm.fr/inserm-00173074}

Submitted on 18 Sep 2007

HAL is a multi-disciplinary open access archive for the deposit and dissemination of scientific research documents, whether they are published or not. The documents may come from teaching and research institutions in France or abroad, or from public or private research centers.
L'archive ouverte pluridisciplinaire $\mathbf{H A L}$, est destinée au dépôt et à la diffusion de documents scientifiques de niveau recherche, publiés ou non, émanant des établissements d'enseignement et de recherche français ou étrangers, des laboratoires publics ou privés. 


\section{Characteristics of undiagnosed diabetes in community-dwelling French}

\section{elderly: the 3C study}

I Bourdel-Marchasson, $\mathrm{MD}, \mathrm{PhD}^{1}$, C Helmer, $\mathrm{MD}, \mathrm{PhD}^{2}$, $\mathrm{P}$ Barberger-Gateau, $\mathrm{MD}, \mathrm{PhD}^{2}$,

E Peuchant, $\mathrm{PhD}^{3}$, B Février, $\mathrm{MD}^{4}, \mathrm{~K}$ Ritchie, $\mathrm{PhD}^{5}$, J-F Dartigues, $\mathrm{MD}, \mathrm{PhD}^{2}$

Running title: Undiagnosed diabetes in the elderly

1: Geriatric Department, Hôpital Xavier Arnozan, 33604 Pessac cedex, France and

UMR.5536 CNRS/University Bordeaux 2, 146 rue Léo Saignat, 33000 Bordeaux, France

2: INSERM U.593, Université Bordeaux 2, 146 rue Léo Saignat, 33076 Bordeaux cedex,

France

3: Laboratoire de Biologie de la Différenciation et du Développement, EA 3674, University

Bordeaux 2, 146 rue Léo Saignat, 33076 Bordeaux cedex, France

4: INSERM U.708, Hôpital La Salpêtrière, 75651 Paris cedex, France

5: INSERM E0361, Hôpital La Colombière, 34093 Montpellier Cedex 5, France

Corresponding author:

I Bourdel-Marchasson, Geriatric Department, Hopital Xavier Arnozan, 33604 Pessac cedex

France

Phone: (33) 5576565 71; Fax: (33) 557656560

E-mail: isabelle.bourdel-marchasson@ chu-bordeaux.fr 


\section{ABSTRACT}

We aimed to assess clinical and socio-demographic characteristics of undiagnosed diabetes, including glucose control, in French community-living elderly people. Diagnosed and undiagnosed diabetes, impaired fasting glucose (IFG), and characteristics of subjects were assessed by interview, clinical examination and fasting blood glucose measures at the baseline visit of the Three-City (3C) study including 9294 people over 65 in three urban areas in France. In the Bordeaux sample, HbA1c was measured in diabetic and IFG subjects and in a sub-sample of non-diabetic subjects. The proportion of diagnosed diabetes, undiagnosed diabetes and IFG was respectively $8.2 \%, 1.4 \%$ and 3.6\%. Diabetic and IFG subjects were more likely to be men, to suffer from hypertension and to be overweight. They were less likely to have a high income and more likely to have a lower educational level. These factors were unrelated to knowledge of diabetic status. In the Bordeaux sub-sample, $19.6 \%$ of the diagnosed diabetic subjects and $16.1 \%$ of those undiagnosed had an HbA1c greater than $8 \%$. Prevalence of ischemic heart disease was more common in diagnosed than in undiagnosed diabetic subjects ( $p=0.021$ ). A significant number of undiagnosed elderly had poor glucose control suggesting a potential benefit for diabetes screening in the elderly.

Key words - diabetes mellitus; blood glucose; epidemiology; aged; aged, 80 and over; comorbidity; socioeconomic factors 


\section{Introduction}

The benefits of early detection of type 2 diabetes $[1,2]$ is currently a topic of considerable debate. In adults under 60 years of age, efficient control of diabetes has proven highly efficacious in the prevention of microvascular complications and has borderline effects on cardiovascular morbidity in newly diagnosed type 2 diabetes [3, 4]. Furthermore, within the same population, the risk of developing any diabetic complication was associated with the level of blood glucose; the lowest risk being in those with an $\mathrm{HbA}_{1 \mathrm{c}}$ value in the normal range [5]. In addition, it has also been shown that controlling blood pressure in type 2 diabetic subjects leads to a significant reduction in diabetes-related morbidity [6]. These observations point to the clinical importance of preventive strategies, notably early diagnosis of type 2 diabetes. Nevertheless, using retrospective epidemiological data in a population-based study, no evidence of increased health service use during a ten-year observation period has been observed in subjects remaining undiagnosed [7]. However, in this latter study, other endpoints such as mortality were not analysed on the basis of the knowledge of diabetic status.

In the oldest age group (over 65 and even over 80), the impact of diabetes control is still less known, but as younger subjects, this population could benefit from preventive strategies. Indeed, the prevalence of diagnosed diabetes in adults over 65 is high, varying from 10.0 to $16.9 \%$ [8-10], and tends to decrease over 80 . Prevalence of undiagnosed diabetes is less often studied, but in the adult population over 20 it has been estimated that this prevalence is half that of diagnosed diabetes [11]. In Canadians aged 60-74, the prevalence of undiagnosed diabetes was even greater and was found to be equal to that of diagnosed diabetes in women, and between one third to a half in men [7]. Thus undiagnosed diabetes appears to be quite common. However, little is currently known concerning the clinical and socio-demographic characteristics of these individuals whereas they should constitute a target for the screening and management of impaired glucose level and its associated complications. 
We aimed to describe the socio-demographic and clinical features and the level of glycemic control of free living elderly subjects with undiagnosed diabetes, and to compare them with those of diagnosed diabetic subjects and non-diabetic subjects.

\section{Research design and methods}

\subsection{Study population}

The Three-City (3C) Study is a longitudinal epidemiological study of vascular risk factors of dementia conducted in three areas of France: Bordeaux (south-west), Dijon (northeast) and Montpellier (south-east). The study design and characteristics of the three population samples is described in detail elsewhere. [12]. The cohort was recruited and examined for the first time between March 1999 and March 2001. The study protocol was approved by the Ethical Committee of Kremlin-Bicêtre Hospital (Paris, France). To be eligible for recruitment into the study, subjects had to be i) living in these cities or their suburbs and registered on the electoral rolls, ii) aged 65 years and over, and iii) not institutionalised. Eligible inhabitants of the selected districts were then invited to participate by a letter and were then contacted by phone with an acceptance rate of $37 \%$, giving a total cohort of 9,294.

Data were collected during a face-to-face interview using a standardised questionnaire. General data included: demographic characteristics, education level, occupational history, daily-life habits and a functional evaluation. Medical history of vascular diseases and vascular risk factors was assessed: hypertension, diabetes, stroke, angina pectoris, myocardial infarction, lower limb ischemic peripheral vascular disease, cardiac and vascular surgery. When subjects reported diabetes, they should specify the age of onset of this pathology. Examination included an inventory of all drugs used regularly during the preceding month. The clinical examination also included measurement of systolic and diastolic blood pressure, anthropometric measures (including height and weight), neuropsychological testing, and 
fasting blood sampling. Biological results were given to the subjects and their general practitioners.

\subsection{Diagnosis of diabetes}

Subjects were considered as diagnosed diabetic subjects if they reported diabetes and/or if they used hypoglycemic agents including insulin, sulfonylureas, metformine, acarbose and miglitol. In addition, subjects not classified as diagnosed diabetic subjects because they do not report diabetes and do not receive anti-diabetic treatment, were considered as having undiagnosed diabetes when fasting glucose level was equal or over 7 $\mathrm{mmol} / \mathrm{L}$ and were considered as having Impaired fasting glucose (IFG) when fasting glucose level was between 6.1 (included) and 7 (excluded) mmol/L. The classification was based on WHO criteria [13].

\subsection{Glucose control}

Evaluation of glucose control was based on HbA1c (percent) measurement in subjects living in the Bordeaux area. HbA1c was determined in diabetic and hyperglycemic subjects and for a sample of 227 non-diabetic controls randomly matched on age and sex. HbA1C was determined by ion exchange low-pressure liquid chromatography (LPLC). Three classes of $\mathrm{HbA1c}$ were created in reference to current treatment goal threshold guidelines [14]: less or equal to $7 \%$, from 7 (excluded) to $8 \%$ (included), and over $8 \%$.

\subsection{Descriptive and adjustment variables}

Variables considered were: age, sex, education level (at least primary school level validated by a diploma, versus no diploma), and monthly income (less than 750 euros, between 750 and 1500 euros, between 1500 and 2250 euros, and more than 2250 euros). Time interval from the previous blood analysis was assessed to evaluate access to health care or health seeking practices (less than one month, less than six months, less than one year, more than one year). Lifestyle included use of alcohol (number of glasses per week) and tobacco 
(classified as never, former and current smokers). Self-rated health was assessed on a 5-level scale from very good to very poor. Hypertension was defined as systolic blood pressure equal to or greater than $160 \mathrm{~mm} \mathrm{Hg}$ and/or diastolic blood pressure equal to or greater than $95 \mathrm{~mm}$ $\mathrm{Hg}$, and/or anti-hypertensive treatment. Body Mass Index (BMI) (weight/size ${ }^{2}$ ) was calculated.

Subjects were classified as having cardiovascular ischemic disease if they complained of angina pectoris, and/or had antecedents of myocardial infarction, coronary bypass or coronary angioplasty. Antecedents of stroke or carotid angioplasty were classified as cerebrovascular disease. Subjects were classified as having lower limb ischemic vascular disease if they reported to have it or had undergone surgery for lower limb ischemic vascular disease.

Cognition was evaluated using the Mini Mental State Examination (MMSE) which provides a global cognitive functioning score [15] ranging from 0 to 30 , the highest score corresponding to better cognition. Depressive symptoms were assessed using the Center for Epidemiologic Studies-Depression (CES-D) scale [16]. Subjects were considered as having depressive symptomatology when they scored 17 or more for men and 23 or more for women on the CES-D scale or when the test was not administered due to a reported diagnosis of depression.

\subsection{Analysis}

Statistical analysis was performed using the SAS system (8.2, SAS institute Inc., Cary NC, USA). Values are expressed as means with Standard Deviations (SD) or as percentages. Chi-square tests and ANOVA were used to compare qualitative or quantitative variables. Polynomial regression models were performed to test characteristics of the subjects according to their diabetic status. Logistic regression models were performed to compare the characteristics of diagnosed and undiagnosed diabetic subjects. 


\section{Results}

\subsection{Diabetes diagnosis}

Diagnosis of diabetes was evaluated in the 8654 subjects (93.1\% of the total cohort) who accepted the fasting blood sampling. Among them, 830 had diabetes $(9.6 \%)$ (including 706 with diagnosed diabetes) and 315 (3.6\%) had IFG. The proportion of diabetics was $10.4 \%$ in Bordeaux, 9.3\% in Dijon and 9.5\% in Montpellier, the observed differences not being significant $\left(\chi^{2}=1.63, P=.443\right)$.

Among the 830 diabetic subjects identified in our cohort, 124 (14.9\%) had unrecognized diabetes, thus giving a proportion of undiagnosed diabetes in this sample of $1.4 \%$. The proportion of undiagnosed diabetes was found to be the same in the three cities $\left(\chi^{2}\right.$ $=2.31, P=.315)$.

Date of onset of diabetes was assessed in 671 diagnosed diabetic subjects and the mean diabetes duration was found to be 13 years (SD: 11.4). Age of onset could be assessed only for subjects aware of their pathology (i.e. 706 diagnosed subjects minus 20 subjects treated without reporting a diabetes, thus 686 subjects). Fifteen more subjects were missing because they did no answer the question.

A total of $545(77.2 \%)$ of the diagnosed diabetic subjects were treated with hypoglycemic agents. Of these 545 drug-treated subjects, $496(91.0 \%)$ used oral treatment alone, $35(6.4 \%)$ used insulin alone and $14(2.6 \%)$ both. The distribution of hypoglycemic treatment regimes did not differ between the three centers $(P=.11)$. Only 20 subjects were receiving anti-diabetic treatment without reporting diabetes.

Demographic characteristics of the subjects according to diabetes status are given in Table 1. Age did not differ between diabetic, IFG and non-diabetic subjects $(P=.272)$; however, undiagnosed diabetic subjects were older than diagnosed diabetic subjects $(P=.018)$. Diabetic subjects, particularly those with diagnosed diabetes, and IFG subjects 
were more often men $(P<.001)$. Whatever the age category, frequency of diabetes was lower in women than in men $(P<.001)$ although this difference was not statistically significant in the 85 years and over group $(P=.190)$.

The distribution of HbA1c measures according to glycemic status is shown in Table 2. In this sub-sample, $16.1 \%$ of the undiagnosed diabetic subjects had an HbA1c greater than 8\%. This proportion was lower but close to that found in diagnosed diabetic subjects (19.6 \%). In IFG subjects, fewer had HbA1c values over 8\%. However, an HbA1c greater than 7\% was found in $12 \%$ of this group. In addition, 29 more subjects in the IFG group had HbA1c equal to or higher than $6.1 \%$, which leads to a total of 37 subjects $(55.2 \%)$ with HbA1c greater than $6.1 \%$ in this group, compared to 4 subjects $(1.8 \%)$ in the non-diabetic subjects.

\subsection{Social and clinical characteristics of subjects}

The characteristics of undiagnosed, diagnosed, IFG and non-diabetic subjects are given in Table 3. Diabetic subjects had a lower educational level than non-diabetic subjects, but knowledge of diabetic status was not related to educational level. Diabetic subjects less often had a high income, but income did not differ according to the knowledge of diabetic status. Overall, the delay from previous blood sampling differed according to diabetic status. It was similar in non-diabetic, IFG and undiagnosed diabetic subjects but was lower in diagnosed diabetic subjects. As expected, BMI was higher in diabetic and IFG subjects than in non-diabetic ones. Undiagnosed diabetic subjects had a higher BMI than diagnosed subjects. Tobacco consumption differed slightly according to diabetic status, with both diagnosed and undiagnosed diabetics more often being former smokers.

Diabetic subjects more often evaluated their health as poor or very poor than nondiabetic ones, particularly diagnosed diabetic subjects. Diabetes was significantly associated with higher depressive symptom scores with a trend of higher rates of depressive 
symptomatology in diagnosed compared to undiagnosed subjects. Slightly lower MMSE scores were found in diabetic subjects; this difference was still significant after adjustment for educational level in addition to age and sex $(P=.003)$. However, MMSE did not differ between diagnosed and undiagnosed subjects.

Decreasing rates of cardiovascular disease were observed, descending in order from diagnosed diabetic subjects, to undiagnosed, IFG subjects and to non-diabetic ones. This was particularly marked for ischemic heart diseases, while in lower limb ischemic vascular disease or cerebrovascular disease the trend was weaker. However, only the diabetic subjects and particularly those who were diagnosed had a significantly higher rate of cardiovascular disease than non-diabetic subjects. Both diagnosed and undiagnosed diabetic subjects had elevated rates of hypertension (about 84\%) compared to the non-diabetic ones (about 60\%). Hypertension was also more frequent among IFG than among non-diabetic subjects. After adjustment for age, sex, cardiovascular diseases and tobacco consumption, hypertension in diabetic and IFG subjects was still more frequent $(\mathrm{p}<.001)$. When considering only the measures of blood pressure but not the antihypertensive treatment, the same trend was obtained, high blood pressure being observed in $41.4 \%$ of diagnosed diabetic subjects, $46.2 \%$ of undiagnosed ones, $38.5 \%$ of IFG subjects and $29.4 \%$ of non-diabetic subjects.

\section{Discussion}

In the $3 \mathrm{C}$ study undiagnosed diabetes affected $1.4 \%$ of the cohort compared to an overall diabetes proportion of $9.6 \%$. Undiagnosed and diagnosed diabetic subjects were predominantly male, had a lower educational level, higher BMI and higher hypertension rate in comparison to non-diabetic subjects.

The proportion of undiagnosed cases among total diabetes cases was low (14.9\%) compared to the few previous published studies, leading to a low estimated proportion of undiagnosed diabetes $(1.4 \%)$ in the general older population of the $3 \mathrm{C}$ study. In the USA, the 
rate of undiagnosed diabetes varies from $15 \%$ in older diabetic subjects [11] to one third [17], with rates of $50 \%$ being reported in Canadian women [7]. It is likely, however, that our estimates represent a slight over-estimation. In the subsample of the cohort for whom $\mathrm{HbA1c}$ levels were obtained, $50 \%$ of the undiagnosed diabetic subjects (16 among 31) had an HbA1c lower or equal to $7 \%$, and 5 subjects had values lower than $6.1 \%$. In these latter subjects who were receiving neither dietary advice nor drugs, diabetic status was questionable.

The proportion of undiagnosed diabetes cases among the total cases increased with age. This could be due to a failure on the part of physicians to give a formal diagnosis of diabetes in cases of moderate fasting blood glucose increase in very elderly patients if no treatment was prescribed. However, it is difficult to conclude on this point given the small number of very elderly subjects in the sample.

A noticeable feature of these undiagnosed diabetic older subjects was the high percentage of treated and untreated hypertension. This rate of hypertension was equivalent to that found in diagnosed elderly diabetic subjects. Our study was a cross-sectional study, which did not allow us to establish the direction of the association between pathologies and diabetes. However, it has already been shown in younger populations that undiagnosed diabetes is associated with a higher prevalence of hypertension, obesity, an unfavourable lipid profile and evidence of nephropathy and retinopathy when compared to normoglycemic individuals $[7,18]$. In a Danish population under 60, age, male sex, BMI over 25 or over 30 and hypertension were shown to be independent predictors for undiagnosed diabetes [19]. In a study focused on older subjects, a history of hypertension was found to be an independent risk factor for having undiagnosed diabetes along with male sex and high BMI [17]. Furthermore, both hypertension and antihypertensive therapy were found to be independent risk factors for type 2 diabetes in people under 65 [20]. In addition, the rate of cardiovascular disease, especially ischemic heart disease, was higher in diagnosed than in undiagnosed diabetic 
subjects in our study. Since it is an observational cross-sectional study, this rate could have been underestimated in the non-diabetic population, as well as in the undiagnosed diabetic population, due to the usual active search for such complications once a diagnosis of diabetes has been made. A prospective study including subjects considered at baseline as having successfully aged has shown that diagnosed and newly diagnosed diabetes, but not IFG, was associated with a similar increased risk for unsuccessful ageing during a mean 8-year observation period [21]. Thus, undiagnosed diabetic subjects may still benefit from preventive measures targeting cardiovascular disease.

Undiagnosed elderly diabetic subjects seemed to be clinically monitored in the same way as IFG and non-diabetic ones, with a similar delay from the previous blood sampling. Thus, our results do not support the hypothesis that undiagnosed diabetic subjects have less access to medical attention than other subjects, given our somewhat limited definition of health access. In case of diagnosed diabetes, subjects were more often monitored but not in accordance with standard guidelines (only half of them underwent blood sampling in the previous 6 months).

We have performed HbA1c dosages only in the city of Bordeaux and could have introduced a bias. However, there was no difference for diabetes prevalence and diabetes duration, proportion of undiagnosed diabetes according to the cities and thus the results found in Bordeaux could reflect the reality of the whole population of the 3 cities. It is important to note that glycemic control was the same in both undiagnosed and diagnosed diabetic subjects, whereas $77 \%$ of the latter received a hypoglycemic treatment. Around half of the undiagnosed and diagnosed diabetics had an HbA1c higher than 7\% and were thus at high risk of microvascular complications according to previous research [7]. We could thus conclude that screening for undiagnosed diabetes and the implementation of a treatment program would have significant public health benefits. 
Diagnosis of diabetes was based on self-reported diabetes, anti-diabetic drug use and fasting glucose values that were only measured once. As the diagnostic criteria of ADA (American Diabetes Association) require two independent fasting samples, some subjects may have been misclassified. In the Bordeaux sample, we also asked subjects about diabetic diet. Among the 84 subjects who declared a diabetic diet, only 2 had not reported either diabetes or use of hypoglycemic agents: one has been classified as undiagnosed and the other as IFG on the basis of fasting glucose level. When considering HbA1c values equal to or higher than $6.1 \%$ [22] in the Bordeaux group, misclassification could have occurred in 3 cases who were classified as non-diabetic subjects and whose $\mathrm{HbA} 1 \mathrm{c}$ was higher than $6.1 \%$, representing a potential error of $0.6 \%$. In addition, 29 more subjects in the IFG group could have been classified as diabetics on the basis of $\mathrm{HbA1c}$ equal to or higher than $6.1 \%$ which leads to a total of 37 subjects $(55.2 \%)$ with $\mathrm{HbA} 1 \mathrm{c}$ greater than $6.1 \%$ in this group, compared to 4 subjects $(1.8 \%)$ in the non-diabetic subjects. However, none of these possibly misclassified subjects displayed HbA1c values higher than $6.5 \%$. Thus, a combination of interview and fasting blood glucose values interpreted according to WHO criteria [13] seems to provide adequate subject classification among glycemic status categories.

Despite these limitations, our study showed that undiagnosed diabetes was present in $1.4 \%$ of the older population of $3 \mathrm{C}$ study and in about $15 \%$ of all diabetic subjects while both have the same prevalence of hypertension and overweight. Furthermore, a significant proportion of undiagnosed diabetic subjects had a poor glucose control, and thus could benefit from diabetes treatment and follow-up. These results can contribute to a better understanding of the features of undiagnosed diabetes in the elderly population and advocate for a better screening and management of these patients. 


\section{ACKNOLEDGMENTS}

Partnership and support: The 3C Study has been conducted under a partnership agreement between the Institut National de la Santé et de la Recherche Médicale (INSERM), the Victor Segalen Bordeaux II University and Sanofi-Aventis. The Fondation pour la Recherche Médicale funded the preparation and initiation of the study.

The 3C-Study is also supported by the Caisse Nationale Maladie des Travailleurs Salariés, Direction

Générale de la Santé, MGEN, Institut de la Longévité, Agence Française de Sécurité Sanitaire des

Produits de Santé, Conseils Régionaux of Aquitaine and Bourgogne, Fondation de France, Ministry of Research - INSERM Programme "Cohortes et collections de données biologiques". 



\section{REFERENCES}

[1] P. Streets, Screening for type 2 diabetes. Undiagnosed diabetes must be detected, BMJ 323 (2001) 453-4;

[2] N.J. Wareham S.J. Griffin, Should we screen for type 2 diabetes? Evaluation against National Screening Committee criteria, BMJ 322 (2001) 986-8.

[3] Effect of intensive blood-glucose control with metformin on complications in overweight patients with type 2 diabetes (UKPDS 34). UK Prospective Diabetes Study (UKPDS) Group, Lancet 352 (1998) 854-65.

[4] Intensive blood-glucose control with sulphonylureas or insulin compared with conventional treatment and risk of complications in patients with type 2 diabetes (UKPDS 33). UK Prospective Diabetes Study (UKPDS) Group, Lancet 352 (1998) 837-53.

[5] I.M. Stratton, A.I. Adler, H.A. Neil, D.R. Matthews, S.E. Manley, C.A. Cull, et al., Association of glycaemia with macrovascular and microvascular complications of type 2 diabetes (UKPDS 35): prospective observational study, Bmj 321 (2000) 405-12.

[6] Tight blood pressure control and risk of macrovascular and microvascular complications in type 2 diabetes: UKPDS 38. UK Prospective Diabetes Study Group, BMJ 317 (1998) 703-13.

[7] T.K. Young C.A. Mustard, Undiagnosed diabetes: does it matter?, CMAJ 164 (2001) 24-8.

[8] I. Bourdel-Marchasson, B. Dubroca, G. Manciet, A. Decamps, J.P. Emeriau, J.F. Dartigues, Prevalence of diabetes and effect on quality of life in older French living in the community: the PAQUID Epidemiological Survey, J Am Geriatr Soc 45 (1997) 295-301.

[9] C. Castell, R. Tresserras, J. Serra, A. Goday, G. LloverasL. Salleras, Prevalence of diabetes in Catalonia (Spain): an oral glucose tolerance test-based population study, Diabetes Res Clin Pract 43 (1999) 33-40. 
[10] K. Rockwood, M.H. Tan, S. Phillips, I. McDowell, Prevalence of diabetes mellitus in elderly people in Canada: report from th Canadian Study of Health and Aging, Age Ageing 27 (1998) 573577.

[11] M.I. Harris, K.M. Flegal, C.C. Cowie, M.S. Eberhardt, D.E. Goldstein, R.R. Little, et al., Prevalence of diabetes, impaired fasting glucose, and impaired glucose tolerance in U.S. adults. The Third National Health and Nutrition Examination Survey, 1988-1994, Diabetes Care 21 (1998) 51824.

[12] Vascular factors and risk of dementia: design of the Three-City Study and baseline characteristics of the study population, Neuroepidemiology 22 (2003) 316-25.

[13] K.G. Alberti, P.Z. Zimmet, Definition, diagnosis and classification of diabetes mellitus and its complications. Part 1: diagnosis and classification of diabetes mellitus provisional report of a WHO consultation, Diabet Med 15 (1998) 539-53.

[14] A.F. Brown, C.M. Mangione, D. Saliba, C.A. Sarkisian, Guidelines for improving the care of the older person with diabetes mellitus, J Am Geriatr Soc 51 (2003) S265-80.

[15] M.F. Folstein, S.E. Folstein, P.R. McHugh, Mini-mental state : a practical method for grading the cognitive state of patients for the clinician, J Psychiatr Res 12 (1975) 189-98.

[16] R. Fuhrer, F. Rouillon, La version française de l'échelle CES-D (Center Epidemiological StudiesDepression Scale). Description et traduction de l'échelle d'auto-évaluation., Psychiatrie et Psychologie 4 (1989) 163-166.

[17] L.V. Franse, M. Di Bari, R.I. Shorr, H.E. Resnick, J.T. van Eijk, D.C. Bauer, et al., Type 2 diabetes in older well-functioning people: who is undiagnosed? Data from the Health, Aging, and Body Composition study, Diabetes Care 24 (2001) 2065-70.

[18] M.I. Harris, Undiagnosed NIDDM: clinical and public health issues, Diabetes Care 16 (1993) $642-52$. 
[19] C. Glumer, B. Carstensen, A. Sandbaek, T. Lauritzen, T. Jorgensen, K. Borch-Johnsen, A Danish diabetes risk score for targeted screening: the Inter99 study, Diabetes Care 27 (2004) 727-33. [20] T.W. Gress, F.J. Nieto, E. Shahar, M.R. Wofford, F.L. Brancati, Hypertension and antihypertensive therapy as risk factors for type 2 diabetes mellitus. Atherosclerosis Risk in Communities Study, N Engl J Med 342 (2000) 905-12.

[21] A.B. Newman, A.M. Arnold, B.L. Naydeck, L.P. Fried, G.L. Burke, P. Enright, et al., "Successful aging": effect of subclinical cardiovascular disease, Arch Intern Med 163 (2003) 2315-22. [22] C.L. Rohlfing, R.R. Little, H.M. Wiedmeyer, J.D. England, R. Madsen, M.I. Harris, et al., Use of $\mathrm{GHb}(\mathrm{HbA} 1 \mathrm{c})$ in screening for undiagnosed diabetes in the U.S. population, Diabetes Care 23 (2000) $187-91$. 
Table 1. Demographic characteristics of the Three Cities sample in whom fasting blood sampling was available 1999-2001, N=8654.

\begin{tabular}{rccccc}
\hline Diagnosed & Undiagnosed & Proportion of & IFG subjects & Non-diabetic & To \\
diabetic & diabetic & Diabetes & & subjects \\
subjects & subjects & $(\%)$ in 3-C & & \\
\hline $74.2(5.2)$ & $75.4(6.2)$ & - & $74.4(5.2)$ & $74.1(5.6)$ & 7 \\
44.1 & 54.0 & - & 50.8 & 62.4 & 6
\end{tabular}

Age and sex distribution

$65-74$ years

$\begin{array}{lccccc}\text { Women } & 170 & 32 & 6.6 & 92 & 2751 \\ \text { Men } & 248 & 32 & 13.3 & 87 & 1736 \\ \text { Total } & 418 & 64 & 9.4 & 179 & 4487\end{array}$

75-84 years

$\begin{array}{lccccc}\text { Women } & 128 & 28 & 8.1 & 61 & 1717 \\ \text { Men } & 130 & 19 & 12.9 & 60 & 948 \\ \text { Total } & 258 & 47 & 9.9 & 121 & 2665\end{array}$

$>85$ years

Men
Total
Women

13

7

8.2

Men

17

6

13.5

8

139

Total

30

13

10.4

15 
Table 2. Distribution of HbA1c according to diabetic status in a subsample of 468 subjects from the area of Bordeaux.

\begin{tabular}{|c|c|c|c|c|}
\hline & \multirow[b]{3}{*}{$\mathrm{N}$} & \multicolumn{3}{|c|}{$\mathrm{HbA1c}$} \\
\hline & & $<=7 \%$ & $>7$ and $<=8$ & $>8$ \\
\hline & & $\%$ & $\%$ & $\%$ \\
\hline Diagnosed diabetic subjects & 143 & 55.9 & 24.5 & 19.6 \\
\hline Undiagnosed diabetic subjects & 31 & 51.6 & 32.3 & 16.1 \\
\hline IFG subjects & 67 & 88.0 & 9.0 & 3.0 \\
\hline Non-diabetic subjects & 227 & 100.0 & 0.0 & 0.0 \\
\hline Total & 468 & 81.6 & 10.9 & 7.5 \\
\hline
\end{tabular}


Table 3. Socio-demographic characteristics and health-related features of Three Cities subjects according to their

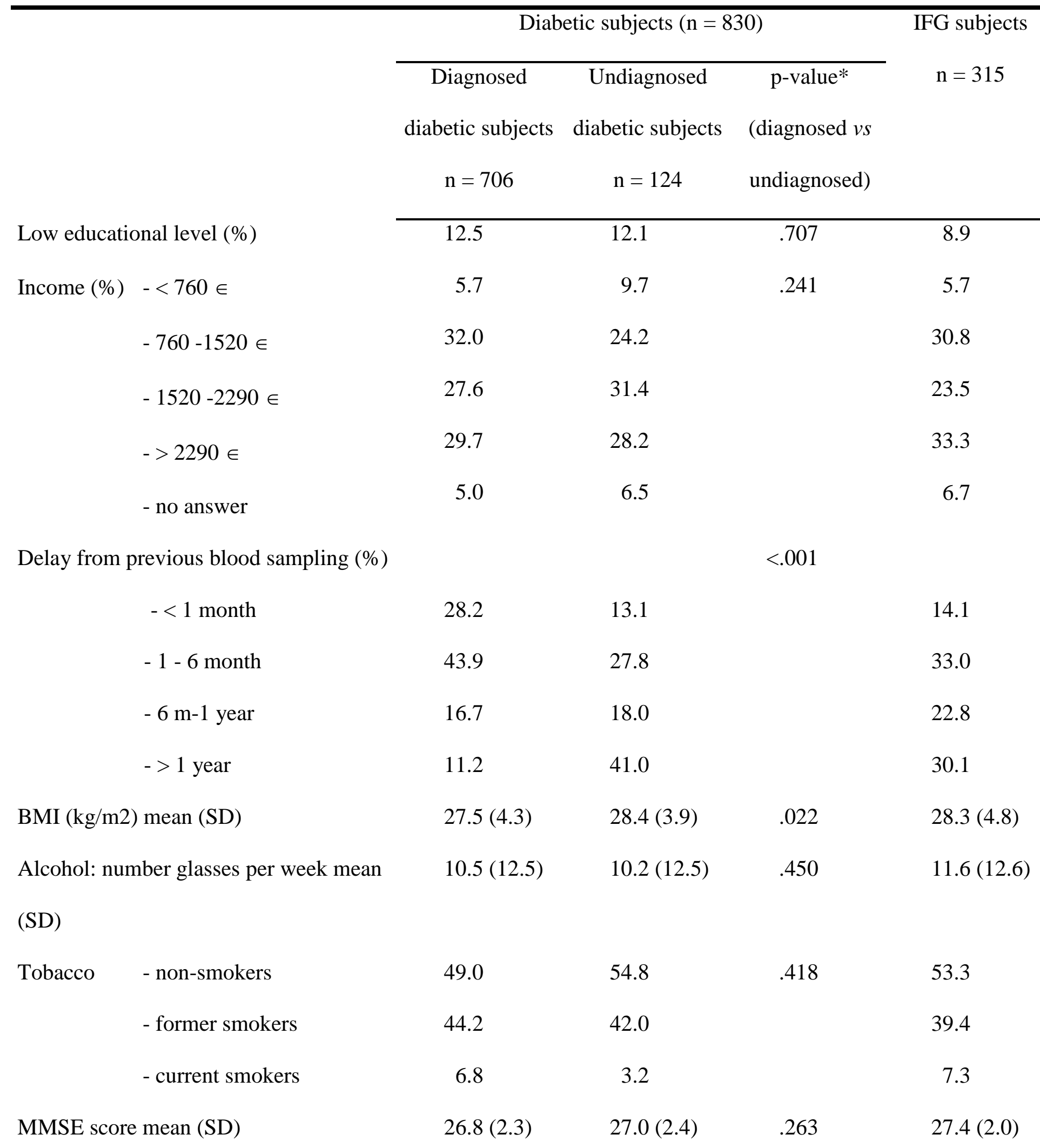




\begin{tabular}{|c|c|c|c|c|c|}
\hline \multirow[t]{3}{*}{ Subjective health } & - very good / good & 47.2 & 55.3 & \multirow[t]{3}{*}{.016} & 58.5 \\
\hline & - fair & 43.9 & 41.5 & & 36.4 \\
\hline & - poor / very poor & 8.9 & 3.2 & & 5.1 \\
\hline \multicolumn{2}{|c|}{ Depressive symptomatology (\%) } & 18.0 & 11.6 & .088 & 15.6 \\
\hline \multicolumn{2}{|l|}{ Hypertension (\%) } & 83.9 & 83.5 & .940 & 75.6 \\
\hline \multicolumn{2}{|c|}{ Ischemic heart disease $(\%)$} & 23.5 & 14.3 & .021 & 7.2 \\
\hline \multicolumn{2}{|c|}{ Lower limb ischemic disease $(\%)$} & 7.0 & 5.9 & .613 & 5.2 \\
\hline \multicolumn{2}{|c|}{ Cerebrovascular disease $(\%)$} & 7.6 & 3.3 & .076 & 5.2 \\
\hline
\end{tabular}

\footnotetext{
* p-value for the odds ratio of undiagnosed diabetes versus diagnosed one, adjusted on age and sex, by logistic regression

$\uparrow \mathrm{p}$-value for the odds ratio of diabetic (together diagnosed and undiagnosed), hyperglycemic, and non-diabetic subjects, adjusted on age and sex, by polynomial regression
} 